\title{
Physical Examination
}

National Cancer Institute

\section{Source}

National Cancer Institute. Physical Examination. NCI Thesaurus. Code C20989.

A systemic evaluation of the body and its functions using visual inspection, palpation, percussion and auscultation. The purpose is to determine the presence or absence of physical signs of disease or abnormality for an individual's health assessment. 